\title{
ELISO (1928) EN HET NETWERK VAN NEDERLANDSE POORTWACHTERS BIJ DE VERTONING VAN ZWIJGENDE FILMS MET MUZIKALE BEGELEIDING
}

Zwijgende films hebben een imagoprobleem. Ze zijn onbekend en onbemind; er bestaat weinig spontane vraag naar voorstellingen van zwijgende films met live muzikale begeleiding. In dit artikel*) wil ik de processen van selectie en reputatievorming in dit specifieke deel van het filmerfgoed behandelen. Maar het lijkt verstandig te beginnen met een korte verdediging van de relevantie van de vertoning van zwijgende film.

Diversiteit in filmaanbod is waardevol - anders belanden we bij het schrikbeeld van louter blockbusters in filmzalen en simpele selectie van audiovisuele stimuli (content) op basis van kijkcijfers en winstbejag. De zwijgende film is een historische deelverzameling met eigenzinnige vormen en varianten van filmische expressie. Veel filmmakers uit die periode, van ongeveer I895 tot I930, zijn te beschouwen als vroege meesters van de filmkunst. Geen beginnelingen maar volwaardige kunstenaars die werk maakten met een tijdloze zeggingskracht. Wie het domein van de zwijgende film betreedt krijgt toegang tot een visuele en veelzijdige verbeelding, zonder gesproken dialogen. Alle woorden zitten opgesloten in de tussentitels. De film bevat bijna uitsluitend fotografische beelden. Dit biedt een podium voor muzikale begeleiding.

In de praktijk zijn de mogelijkheden bij de presentatie van zwijgende films echter beperkt. Het is een breekbaar medium dat veel professionele zorg en koestering vergt, alleen al omdat het materiaal minstens tachtig jaar oud is en de projectiesnelheid grillig varieert per film. De kernvraag is hier tweeledig: welke logistieke obstakels komen we tegen als we een zwijgende film in de bioscoopzaal met live muzikale begeleiding willen vertonen? En: welke artistieke criteria worden gehanteerd bij het selectieproces? Ofwel: wie bepaalt op welke wijze welke zwijgende films anno 2008 beschikbaar zijn? En wie selecteert op welke wijze welke zwijgende films geschikt bevonden worden voor vertoning in de filmzaal, op het grote doek, met live muzikale begeleiding? Voor de formulering van een mogelijk antwoord op deze brede vragen naar de institutionele achtergrond van de vertoning van dat filmerfgoed ligt de focus op twee 
aspecten. Ten eerste is een aantal noodzakelijke voorwaarden te onderscheiden bij de zaalvertoning van een zwijgende film - met als eerste eis de beschikbaarheid van een goede rechtenvrije kopie. En ten tweede is een aantal gatekeepers en keuzemomenten te duiden. Een trendwatcher als Jeremy Rifkin benadrukt in zijn boek The Age of Access uit 2000 het toenemende belang en de groeiende macht van gatekeepers:

'Power, in the coming era, belongs to the gatekeepers who control both access to the popular culture and the geographic and cyberspace netwerks that expropiate, repackage, and commodify the culture in the form of paid-for personal entertainment and experiences. ${ }^{\text {'I }}$

Rifkin schetst de contouren van de omslag naar een nieuwe cultuur in de eenentwintigste eeuw, waarin de toegang tot belevenissen waardebepalend zal zijn. Dit is een interessant toekomstperspectief, want ook de toegang tot filmerfgoed zou verkocht kunnen worden als een kostbare ervaring.

De noodzakelijke voorwaarden en de keuzemomenten bij de presentatie van zwijgende films wil ik bespreken aan de hand van een specifiek voorbeeld: de vertoning van de relatief onbekende Georgische zwijgende film ELIso (Nikolaj Sjengelaja, I928) in de Nederlandse filmzalen. ${ }^{2}$ Dit voorbeeld is gekozen omdat deze film in Nederland in 2008 eindelijk te zien is geweest in een complete versie en met een nieuw samengestelde muzikale begeleiding. Waarom dit zulk goed nieuws is wordt hierna toegelicht.

\section{Een ten onrechte in de vergetelheid geraakt meesterwerk}

Met de inroostering van een vertoning van ELISo kiest de eigentijdse programmeur voor een niet-canonieke invulling van het programma. Wat heeft het publiek van vandaag aan een film die tachtig jaar oud is? Daarop zijn drie antwoorden mogelijk die een verbinding leggen met de belevingswereld van filmtoeschouwers in Nederland anno 2008. Ten eerste gaat ELISo over Russische bezetters van een bergdorp in de Kaukasus, rond i864. Het tsaristische leger voert een wrede oorlog; de Russische overheid wil de landbouwgrond en het vee van de dorpsbewoners inpikken. In deze film vervullen de Russen (en de Kozakken) de schurkenrol. Het is onzeker hoe het Georgische publiek in I928 de film zal hebben ervaren, maar voor een publiek in 2008 is het bijna onvermijdelijk de parallel met Tsjetsjenië of Afghanistan te trekken. De Russische aanwezigheid in de Kaukasus en het verzet van de bevolking daartegen heeft zo een tijdloze actualiteit. Ten tweede bevat ELIso een liefdesverhaal over een christelijke held, de schaapherder Vazja, en een islamitische heldin, het dorpsmeisje Eliso. De held redt het vee van de dorpsbewoners en hij waagt zijn leven voor hen bij zijn strijd in een Russische legerpost. Maar toch krijgt hij aan 
het eind van de film te horen: "Je bent anders, en je zult nooit iemand van ons worden". Er is dus sprake van een diepgewortelde maatschappelijke verdeeldheid op basis van godsdienst. Ook dit heeft een tijdloze actualiteit. De heldin laat zich kennen als een jonge zelfbewuste vrouw. Toch kiest ze aan het eind voor 'eigen volk' en niet voor de liefde. Ten derde kan een hedendaags publiek ELISO ook ervaren als een interessant voorbeeld van wereldcinema. Regisseur Shengelaja heeft bijvoorbeeld een goed gevoel voor de visuele aantrekkingskracht van de exotische folklore van zijn geboorteland. Hij situeert het verhaal over onrecht en machtsmisbruik in een decor van weidse berglandschappen. Bij de hedendaagse receptie van deze film kan op de achtergrond het besef een rol spelen dat de actualiteit van een dreigende burgeroorlog in Georgië weinig ruimte laat aan kunst en cultuur. Daarom is aandacht voor het filmerfgoed uit dit door conflicten geteisterde land te beschouwen als een waardevolle aanvulling op de berichtgeving in de nieuwsreportages.

Een meer vertrouwd argument ligt in de status van de filmmaker. Regisseur Nikolaj Sjengelaja (I903-1943) is te beschouwen als één van de grote pioniers van de Georgische cinema. Hij was aanvankelijk een veelbelovend dichter, in de kring van het Futurisme (zoals onder anderen Vladimir Majakovski). Sjengelaja raakte gefascineerd door het filmvak als regie-assistent bij twee films van Kote Mardsjanisjvili en besloot zelf films te gaan maken - bij de toen gloednieuwe Groezija Studio in Tbilisi (in I923 opgericht, één van de eerste studio's in de Centraal-Aziatische republieken van de Sovjet-Unie). Hier maakte hij zijn eerste speelfilm. Zijn debuut eliso (1928) werd meteen een triomf. In de Pravda verschenen positieve commentaren op de film en complimenten voor de toen 25-jarige regisseur. Filmhistorica Denise J. Youngblood beschrijft in I99I ELIso in de volgende lovende bewoordingen:

'The director had strong pictoral and dramatic instincts and good control over the silent film techniques of closeups and rhythmic editing. Eliso's stealthy return to the village is beautifully done, only shadows showing the course of the action. Shengelaia also showed a sense of humor rare in Soviet melodrama, turning a swordfight in a hilarious parody of a Fairbanks swashbuckler. The hero battles Russians in the general's office from under a table, then with his back against a door, holding off dozens of attackers on both sides.'3

Naar mijn mening toont Sjengelaja zich op jonge leeftijd een meester in de montagestijl, in de beste tradities van de Sovjet cinema. In ELIso is sprake van een goed gecomponeerd beeldritme, een bewuste opbouw van een statisch begin naar een dynamisch einde. De film biedt een mix van individuele heldhaftigheid in de strijd tegen de Russen en een lyrische klaagzang over collectief leed van de dorpsbevolking. De hedendaagse toeschouwer kan ELISo dus ook los zien van alle context en de film bekijken en waarderen als een indrukwekkend autonoom kunstwerk, dat door raadselachtige wendin- 
gen van het lot weinig bekendheid geniet en alleen al daarom de aandacht verdient.

\section{De reis van ELISO naar Nederland}

De meeste zwijgende films in de Audiovisuele Collectie Nederland zijn een erfenis van de Nederlandsche Filmliga (overgeleverd in het Uitkijkarchief). Dit is bij ELISO niet het geval geweest. Opmerkelijk is wel dat in I930 bij de Nederlandsche Filmliga in Den Haag en Arnhem een programma is gepresenteerd waarbij een fragment van ELISo vertoond werd, als onderdeel van een pakket filmfragmenten dat door Joris Ivens uit de Sovjet-Unie was meegebracht. ${ }^{4}$

Beschikking over een volledige kopie in goede technische staat is een eerste noodzakelijke voorwaarde voor een filmvertoning. In de filmkluis van het Filmmuseum zijn drie kopieën van ELIso beschikbaar: een $35 \mathrm{~mm}$-archiefkopie, een $35 \mathrm{~mm}$-distributiekopie en een $16 \mathrm{~mm}$-distributiekopie. 5 De $35 \mathrm{~mm}$-archiefkopie is in I967 ontvangen van Sov-export. Deze gift is omgeven met enige raadsels: hoe is deze overdracht toen tot stand gekomen? Wie heeft op welk moment de Nederlandse tussentitels toegevoegd? De archiefkopie was vanaf het begin rechtenvrij, maar niet beschikbaar voor vertoning buiten het Filmmuseum omdat deze kopie de status van unicum heeft. Terecht hanteert de afdeling 'Archival Loans' van het Filmmuseum twee gouden regels bij het uitlenen van de archiefkopieën: de vertoningsrechten moeten geregeld zijn en er moeten minstens twee kopieën in de kluis liggen. Sinds I967 is de $35 \mathrm{~mm}$ archiefkopie van ELISo niet uit de kluis geweest.

In de jaren tachtig werden twee distributiekopieën (een $35 \mathrm{~mm}$ en een I $6 \mathrm{~mm}$ ) van ELISO geïmporteerd. Hoe kon het gebeuren dat deze twee kopieën van een Georgische zwijgende film terechtkwamen in Nederland? Hiervoor keren we terug naar het jaar I980 en naar de distributietak van het Film International Festival in Rotterdam, in I972 begonnen met Huub Bals als directeur. Film International had in I980 een grote tegenslag te verwerken toen in de nacht van i8 op ig december brand uitbrak in de filmopslag; een groot deel van de distributiecollectie ging hierbij verloren. ${ }^{6}$ Met het geld van de verzekering werd voor zover mogelijk de collectie gereconstrueerd met nieuwe kopieën, maar er bleef nog budget over. Directeur Huub Bals liet zich bij zijn keuze voor festivalver-

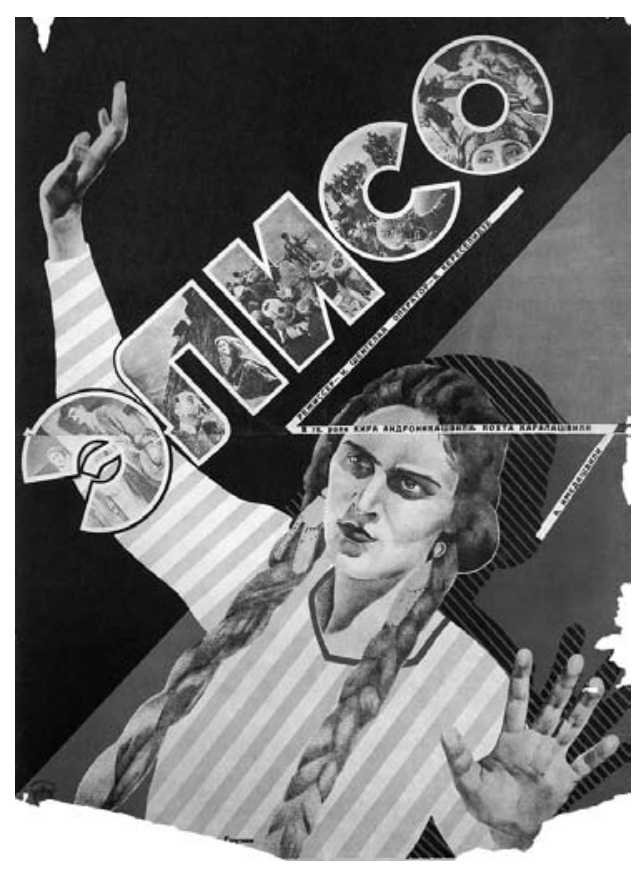

Filmaffiche van ELISO (136 x $101 \mathrm{~cm})$ 1928, Anatoly Belsky. Bron: S.Pack, Film Posters of the Russian Avant-Garde, Köln 1995 
toningen en filmaankopen adviseren door diverse scouts, onder anderen de internationaal gerespecteerde Zwitserse filmjournalist François Albera die de aandacht vestigde op, onder meer, de nieuwe generatie Georgische regisseurs.7 In I98I bevatte de catalogus van het tiende Film International Festival in Rotterdam vijf Georgische films. Dit pakket bestond uit een recente speelfilm (GEORGISCHE KRONIEK VAN DE I9E EEUW van Alexander Rechwiasjwili uit I979), een inhaalslag rondom de naar Frankrijk uitgeweken regisseur Otar Iosseliani (VALLENDE BLADEREN, I967; ER WAS EENS EEN ZANGLIJSTER, I970; PASTORALE, I976) en als verrassende bijvangst de zwijgende film ELISO. ${ }^{8}$ ELISO was één van de vele films in het festivalprogramma (in totaal werden 55 titels vertoond, plus het bijprogramma 'Hollywood B-films'). In de Nederlandse pers werd weinig aandacht aan de film besteed. De meeste belangstelling van de filmcritici ging uit naar de Georgische emigré-regisseur Otar Iosseliani. Hij kreeg geen visum voor Nederland, daarom werd een persconferentie in Lille georganiseerd, waar een selectie van de Nederlandse filmcritici heengevlogen is. De Georgische regisseur Eldar Sjengelaja kon in I98I wel in Rotterdam te gast zijn bij het Film International Festival, onder meer om de film van zijn vader in te leiden. ${ }^{9}$ Met deze aandacht voor de Georgische cinema liep het Film International Festival mondiaal gezien voorop: in I985 volgde het festival van Pesaro met een programma van Georgische films, in I988 het Centre Pompidou en in I989 het Hong Kong Film Festival. ${ }^{\circ}$

In I98I kon distributeur Film International na het festival ruimhartig aankopen, dankzij het verzekeringsgeld. De Georgische films konden bijna allemaal voor vertoning in Nederland behouden blijven, met uitzondering van Rechwiasjwili's GEORGISCHE KRONIEK VAN DE I9E EEUW. ELISO werd meteen in april I98I vertoond tijdens een bescheiden tournee in het Nederlandse filmhuizen-circuit, met een spreiding over drie steden. Bij de vertoningen werd gebruikt gemaakt van de $16 \mathrm{~mm}$-kopie en er was geen sprake van muzikale begeleiding. Dat moet een stugge kijkervaring zijn geweest, maar de reacties van publiek en pers zijn niet gedocumenteerd. ${ }^{\text {II }}$

De kopie van ELISo; het is een verhaal over vele versies. Naast de technische staat van de kopie speelt dus ook de mate van authenticiteit mee: welke versie is historisch gezien de meest juiste? Er is nog geen onderzoek gedaan naar hoe de film er bij de première in I928 uitzag. ${ }^{\text {I2 }}$ ELIso werd in de Sovjet-Unie in I935 opnieuw in distributie genomen, voorzien van een geluidsband met muziek van Iona Toeskia. Regisseur Nikolaj Sjengelaja was toen nog in leven - zijn mening over deze versie is mij onbekend. Het is in elk geval een relatief vroege heruitbreng van een zwijgende film. ${ }^{\mathrm{I} 3}$ Wie benieuwd is naar de versie van ELISO met soundtrack uit I935 moet naar Duitsland, waar ELISo in deze vorm recent nog is vertoond. ${ }^{\mathrm{I}}$ In I964 werd in de Sovjet-Unie van ELISo een versie gemaakt met Russisch commentaar en dialogen. Die versie heeft Nederland wel bereikt in I98I, maar deze 35mm-distributiekopie is niet compleet: er ontbreekt 92I meter (ofwel circa 44 minuten!). De archiefkopie in het Filmmuseum heeft een 
lengte van 2190 meter en is de enige kopie die vrijwel compleet te noemen is. Deze archiefkopie is dus sinds 1967 in Nederland, maar het duurde tot 2008 voordat die vertoond werd. Hoe komt dit?

\section{Gatekeepers in beeld}

Aan elke vertoning van een zwijgende film met muzikale begeleiding gaat een lange reeks keuzemomenten vooraf, waarbij diverse mensen betrokken zijn. De beslissingnemers zijn aan te duiden als gatekeepers. In haar didactisch overzicht van de kunstsociologie, Sociology of the Arts. Exploring fine and popular forms omschrijft Victoria Alexander de term gatekeeping als volgt:

'Gatekeeping, either as individual decisions or organizational outcomes, does not shape the content of art objects directly, but it is a crucial determinant of which art objects, from all those created, the public will actually see.' ${ }^{\text {'5 }}$

De term gatekeepers wordt onder meer gebruikt in onderzoek naar factoren die bepalend zijn voor kunstenaarsloopbanen - inclusief de belemmeringen en stimulansen voor toetreding en doorstroming in de kunstwereld. ${ }^{16}$ Tot voor kort was een aantal conventionele trajecten te onderscheiden in dit labyrint van reputatievorming van kunstenaars en hun werken. Deze 'routekaarten' zijn ook wel aan te duiden met de term decision chain, wat benadrukt dat het gaat om een lineair proces van filtering door gezaghebbende, machtige gatekeepers. Met de opkomst van internet is een tweede kans ontstaan voor alle ambitieuze kunstenaars. Zij kunnen hun faam ook verwerven in het mondiale netwerk van de diverse zelfregulerende sites waarmee het mogelijk is de conventionele paden met de bijbehorende gatekeepers te vermijden.

De presentatie van zwijgende films op internetsites (databanken) en op digitale themakanalen of bij de publieke omroep wordt hier buiten beschouwing gelaten; dat is een verhaal apart. Bij de vertoning van zwijgende films met live muzikale begeleiding in de filmzalen kunnen we een reeks gatekeepers onderscheiden, die ieder op zich keuzes maken: programmeurs, musici, filmarchivarissen, en ... filmhistorici. Een korte rondgang nu langs dit gezelschap van poortwachters, te beginnen bij de programmeurs. Programmeurs van festivals, filmtheaters en filmarchieven staan voor de uitdagende opdracht een noodzakelijke selectie te maken uit respectievelijk de grote hoeveelheid inzendingen bij een festival, of uit de lange reeks filmtitels die uitgebracht worden door de distributeurs, of uit de hoge stapels filmblikken in het archief. Tegenover de overvloed aan filmaanbod staat een schaarste aan vertoningsmogelijkheden, met duidelijk afgebakende limieten door het beperkt aantal zalen en het beperkt aantal time slots. Hoe komt een onbekende, niet-canonieke zwijgende film uit Georgië door dit keuzeproces? In het geval van de presentatie van ELIso is een 
startpunt in de Nederlandse vertoningsgeschiedenis aan te geven met het Film International Festival in I98I, en de aansluitende aankoop door distributeur Film International. Die festivalvertoning heeft weinig sporen nagelaten in de Nederlandse pers en de aansluitende tournee van de film door het land bleef beperkt tot een klein deel van het filmhuizencircuit. In die tijd was nog geen traditie opgebouwd van muzikale begeleiding bij zwijgende films en bij de tournee werd gebruik gemaakt van de $16 \mathrm{~mm}$ kopie, waarin circa 26 minuten ontbreken. Het duurde ongeveer achttien jaar voordat de poort voor een hernieuwde kennismaking met ELISo openging.

De collectie van distributeur Film International kwam begin jaren negentig bij het Filmmuseum terecht - de 35mm-distributiekopie van ELISo werd op 30 juli I990 ontvangen. Voor zover mij bekend is ELISO op 23 mei I999 voor de allereerste keer in het Filmmuseum vertoond, met muzikale begeleiding door één van de huispianisten van het Filmmuseum, Wim van Tuyl. Het bleef bij een éénmalige gebeurtenis. Ook bij deze vertoning zijn nog onbeantwoorde vragen omtrent de intenties van de programmeur en de reacties van pers en publiek. In 2005 en 2007 werd ELISo gepresenteerd in respectievelijk Filmhuis Den Haag en Lantaren/Venster in Rotterdam, beide keren live begeleid door pianist Wim van Tuyl en sopraan Pien Straesser. De programmeurs van deze twee filmtheaters kozen de voorstelling als een eigenwijze invulling van een Cinematheekprogramma dat gewijd was aan de zwijgende Sovjet cinema. Ze beperkten zich bij hun selectie tot de kopieën en de musici die in Nederland beschikbaar waren, maar minder evidente keuzes als ELIso en de combinatie van piano en zang gingen ze niet uit de weg. ${ }^{17}$ In 2008 werd de muzikale live begeleiding aangepast aan de langere versie van de archiefkopie van ELISO die op zondag Io april van dat jaar vertoond werd in het kader van de serie Cine-concerten. Deze serie was samengesteld door programmeurs van het Filmmuseum die aandacht wilden geven aan de recente restauraties van hun archiefmateriaal. ${ }^{18}$ De restauratie van de archiefkopie betekende een primeur; eindelijk was het mogelijk ELIso in Nederland te vertonen in volledige lengte. $\mathrm{Na}$ tachtig jaar was er 'gerechtigheid' voor de maker: zijn versie van I928 was integraal te zien, en bovendien voorzien van een artistiek hoogstaande live muzikale begeleiding. Pianist Wim van Tuyl en sopraan Pien Straesser kozen voor het invoegen van bestaande liederen. Voor de keuze van de liederen hadden de twee musici gezocht in Russisch repertoire. Onderzoek en dramaturgische afwegingen bracht hen op composities van Moessorgski, Tsjaikovsky, Sjedrin en Shostakovitsj. ${ }^{\text {I9 }}$ De uitvoering van ELISo in Amsterdam op Io april 2008 was een heugelijke gebeurtenis, die echter vermoedelijk internationaal weinig weerklank zal hebben. Voorlopig lijkt het erop dat er sprake was van een éénmalige vertoning - op een zondagmiddag, in een zaal met een bescheiden capaciteit van tachtig stoelen. Het is tenslotte niet eenvoudig de aandacht te trekken in het mondiaal netwerk van cinefielen, een gemeenschap die elkaar virtueel treft op internet of periodiek op gespecialiseerde internationale festi- 


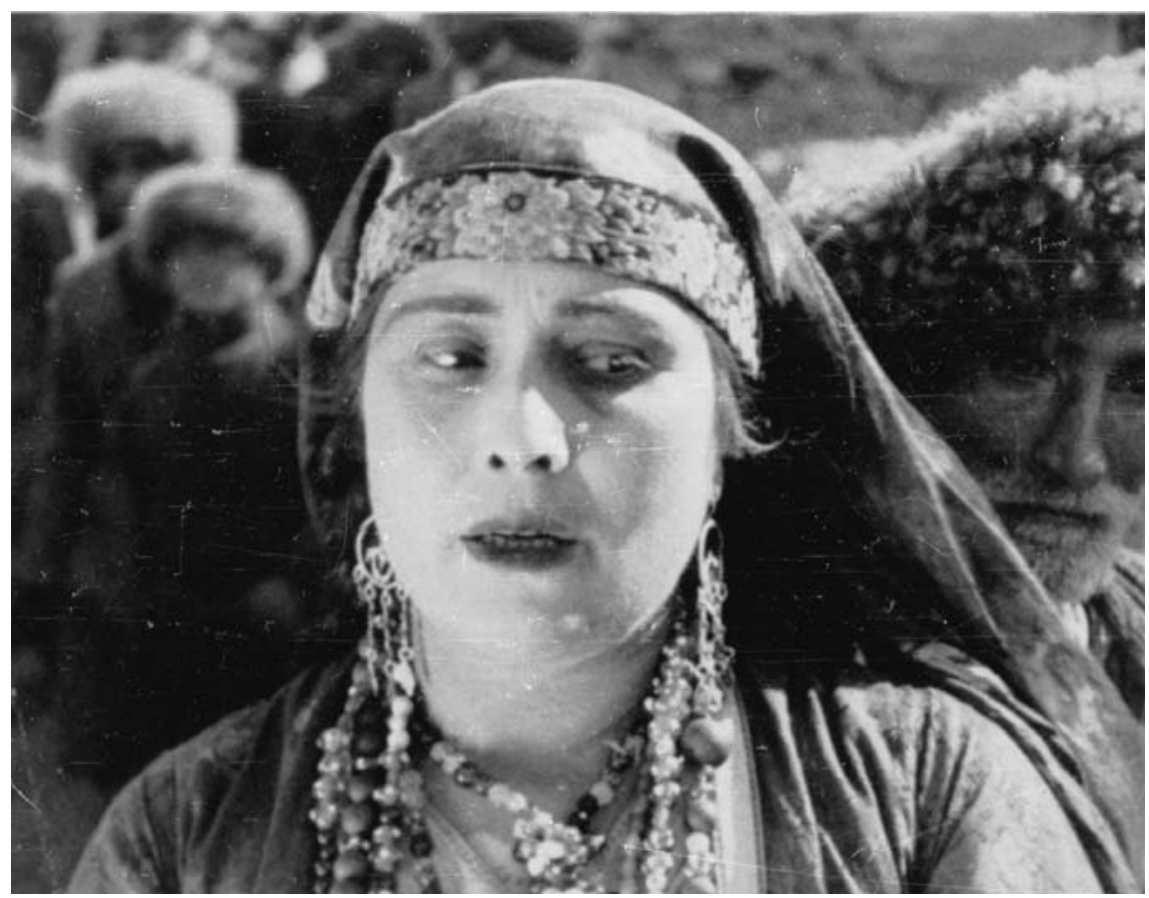

Eliso, 1928.

Bron: Fotocollectie Nederlands Filmmuseum

vals. ${ }^{20}$ Het Filmmuseum heeft bij de herontdekking van BEYOND THE ROCKS (Sam Wood, I922) dankzij een gulle sponsor wel alle wegen van promotie en publiciteit op voorbeeldige wijze kunnen bewandelen, inclusief een DVD-uitgave. $^{2 \mathrm{I}}$

De rol van de filmarchivaris is tweezijdig. Enerzijds reageert hij op aanvragen van de programmeurs voor archival loans, anderzijds fungeert hij ook als gatekeeper door de mogelijkheid van een eigenmachtige keuze welke archieffilm aan de beurt is voor een behandeling in het laboratorium, en de beslissing in welke versie de film hersteld wordt. Dit laatste punt weegt zwaar: de filmarchivaris heeft invloed op hoe het kunstwerk er uiteindelijk uit komt te zien. Een authenticiteitsvraag die ook in andere kunstsectoren speelt, bijvoorbeeld bij de restauratie van gebouwen of de uitgave van middeleeuwse teksten.

De filmarchivaris is een invloedrijke gatekeeper, maar niet almachtig. Bij de beslissing over de restauratie van films is hij op zijn beurt afhankelijk van de besluiten van het ministerie van Cultuur over de financiële ondersteuning van filmarchieven. De minister (of staatssecreataris) van Cultuur staat voorop als boegbeeld, want deze bewindsfiguur heeft formeel gezien de geldkranen voor subsidies in handen. Achter hem staan de ambtenaren van het ministerie en de leden van de Raad voor Cultuur. Het resultaat is een verscheidenheid aan perspectieven en visies op welke stimulerende randvoorwaarden de overheid wil bieden aan de conservering en vertoning van het filmerfgoed. Kernvraag hierbij is: hoeveel subsidie is structureel of incidenteel specifiek beschikbaar voor het 
ontsluiten van filmerfgoed? Op deze vraag is een uitvoerig antwoord mogelijk, met een tijdslijn die bestaat uit de 'Knelpuntennota Audiovisuele Archieven' (in I988 opgesteld door vier grote Nederlandse archieven, in opdracht van minster Elco Brinkman), het 'Deltaplan voor het cultuurbehoud' (in I990 in het leven geroepen door minister Hedy d'Ancona), het advies van de Raad voor Cultuur 'Audiovisuele Collectie Nederland: bron van vreugde, vermaak en zorg' (I998) en het recente samenwerkingsverband tussen zes nationale instellingen onder de naam 'Beelden voor de toekomst'. ${ }^{22}$

\section{Musici in de schaduw van het filmerfgoed}

De musici (en componisten) die zwijgende films begeleiden zijn slechts in beperkte mate te beschouwen als gatekeeper. Ze kunnen weliswaar zelf bepalen welke films tot hun repertoire behoren en welke composities (of improvisaties) gebruikt worden, maar verder behoren ze juist tot de groep die op de poort klopt om toegang te krijgen tot de filmzaal. Ze hebben veel te bieden, ze vragen weinig, maar toch blijft de poort opvallend vaak potdicht. De programmeurs hanteren als argument het gebrek aan budget, het gebrek aan noodzakelijke voorzieningen (zoals een piano, een projector met instelbare snelheid, voldoende podiumoppervlakte voor het filmdoek) en het gebrek aan publieke respons.

Vanaf eind jaren tachtig is internationaal een toenemende aandacht voor het begeleiden van zwijgende films te signaleren. Deze trend is ook in Nederland zichtbaar. In het Filmmuseum is een muziekmedewerker aangesteld, in de persoon van Martin de Ruiter. Evenals zijn voorganger Stefan Ram combineert hij de functies van onderzoeker, impresario, componist en uitvoerend musicus. ${ }^{23}$ Buiten het Filmmuseum heeft Theodore van Houten een indrukwekkende staat van dienst opgebouwd met een reeks van voorstellingen van zwijgende films begeleid door orkest of kleine bezetting. ${ }^{24}$ Als je met een institutionele onderzoeksblik naar het verschijnsel van de muzikale begeleiding van zwijgende films kijkt, dan valt op hoe gering de institutionele verankering op dit gebied nog steeds is in de Nederlandse kunstsector. Hoe vindt een musicus of een componist een begeleidingsopdracht en hoe vindt een programmeur een goede begeleiding? De beantwoording van deze vraag vergt onderzoek van de eigentijdse arbeidsmarkt van componisten en musici die in Nederland betrokken zijn bij de muzikale begeleiding van zwijgende films. Dit is een nog vrijwel onontgonnen onderzoeksterrein, wat begrijpelijk is omdat deze arbeidsmarkt klein is en de beroepsontwikkeling nog steeds in de kinderschoenen staat. Voor een specifiek loopbaanonderzoek bestaat slechts summier materiaal; hier is sprake van een minieme niche. Ook in een niche-markt is een goede institutionele organisatie van de kwaliteitsbeoordeling onmisbaar voor opbouw van beroepsnormen, maar we missen deze basis voor professi- 
onalisering. Het aspect van reputatievorming bij filmbegeleiders kent weinig indicatoren: er bestaat geen opleiding tot filmbegeleider, geen concoursen met prijzen, geen arbeidsplaatsen waar audities voor gedaan moeten worden en in recensies wordt de muzikale begeleiding zelden uitvoerig geëvalueerd. Ook de professionele erkenning is nog steeds minimaal te noemen: in de afgelopen jaren zijn boekingen van filmconcerten in muziektempels en muziekfestivals uitzonderlijk, compositieopdrachten en speelbeurten blijven toevallige incidenten en de honorering is laag. Het beroep van filmbegeleider kent een ontwikkeling die loopt van dagelijkse speelbeurten in de jaren twintig, via werkeloosheid vanaf de jaren dertig tot de status van oproepkracht vanaf de jaren tachtig. Het onderzoek van de historische arbeidsmarkt voor bioscoopmusici in Nederland in de jaren twintig is inmiddels begonnen, voor het recente verleden is vreemd genoeg minder aandacht. ${ }^{25}$

\section{Toegang tot de canon}

Ook een filmhistoricus neemt onvermijdelijk een positie in als gatekeeper. Wellicht is de filmhistoricus zelfs uiteindelijk de meest belangrijke gatekeeper want een film waarover niet geschreven wordt bestaat immers niet meer, die wordt langzaam uit het collectieve geheugen gewist.

Keren we terug naar ELISo. Deze Georgische film bevindt zich puur op geografische basis in de periferie van de filmgeschiedenis van de Sovjet-Unie. Daarnaast heeft de centrale Sovjet overheid in Moskou vanouds de cultuur uit de Centraal-Aziatische republieken onderdrukt of in het beste geval genegeerd. In hoeverre overbruggen de filmhistorici deze geografische afstand en deze historische politieke druk? Ik beperk me hier tot een rondgang langs enkele gezaghebbende filmhistorici. De Amerikaanse filmhistoricus Jay Leyda noemt de film terloops in een opsomming van talloze tijdgenoten van Sjengelaja in zijn standaardwerk Kino: A History of the Russian and Soviet Film (I960):

'After collaborating on two films to learn the medium, Nikolai Shengelaya left his literary career completely to work in films; his first independent film, ELISO, was a triumph. It was suggested by an anecdote recorded by the Georgian writer Kazbegi about a Tsarist scheme in 1864 to evict a village that occupied a desirable piece of land. The film makes the whole village its hero rather than any individual, and a richness of exotic folk-material in it reminds one of wOMEN OF RYAZAN.' ${ }^{26}$

De redactie van het Sovjet standaardwerk Der Sowjetische Film (I974, oorspronkelijke Russische uitgave I969) negeert de film echter, net als Jerzy Toeplitz in zijn Geschichte des Films (1984). ${ }^{27}$ Filmhistorica Denise J. Youngblood bespreekt ELISO positief in haar boek Soviet Cinema in the Silent Era (zie het citaat aan 
ELISO, 1928. Bron: Fotocollectie Nederlands Filmmuseum

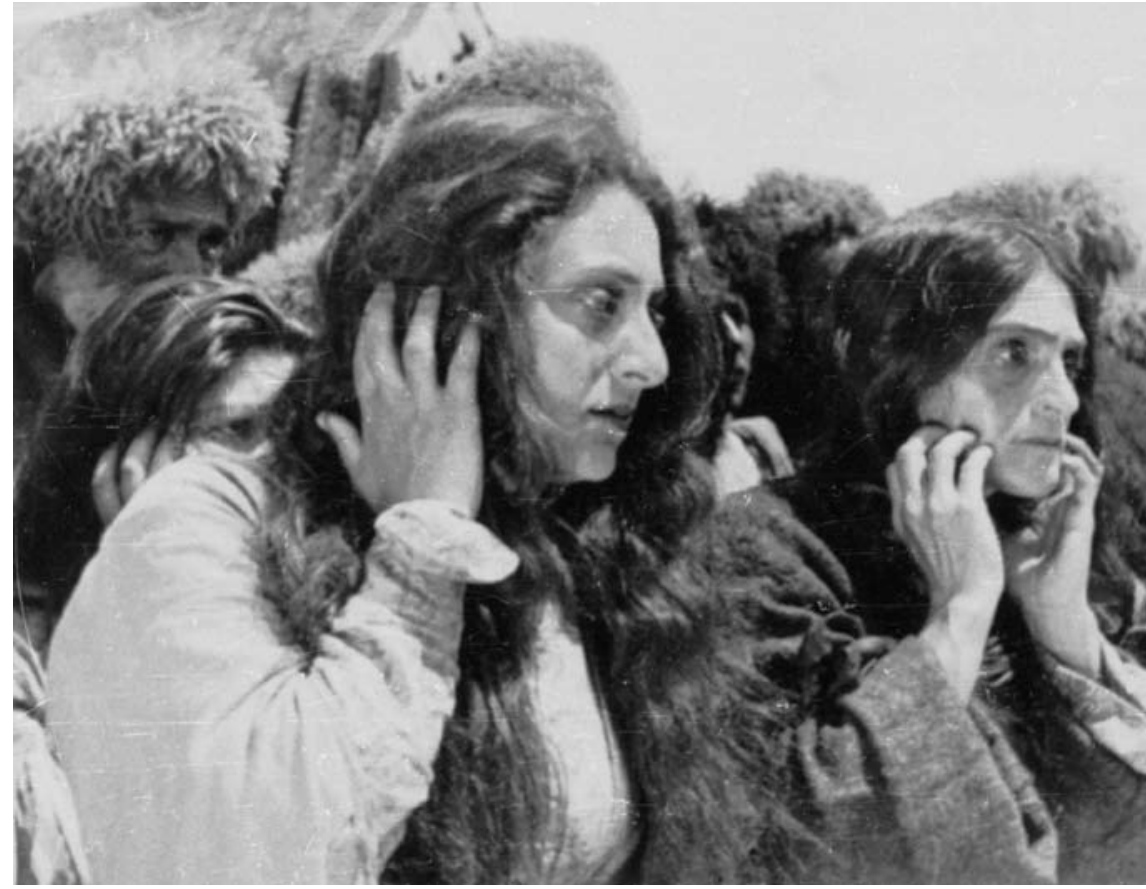

het begin van dit artikel), maar de meeste recente Engelstalige studies van de zwijgende Sovjet cinema als die van Lawton (I992), Kenez (I992) en Gillespie (2000) laten ELIso onvermeld. Ondanks de toenemende aandacht voor wereldcinema en ondanks de toenemende aandacht binnen de filmgeschiedschrijving voor het niet-canonieke corpus is ELIso nog steeds een marginale film. ${ }^{28}$ De zwijgende films die door Russische regisseurs gemaakt zijn in Centraal Azië zijn daarentegen doorgaans wel opgenomen in de canon van elke filmgeschiedenis. Iedere filmhistoricus bespreekt immers onvermijdelijk de documentaire TURKSIB (Victor A. Turin, I928) of de speelfilm STORM OVER AZIË (Vsevolod Poedovkin, I928). Wellicht zijn dit de verkeerde voorbeelden omdat de verklaring van deze filmhistorische aandacht eenvoudig te geven is. Poedovkin was natuurlijk vanaf de jaren twintig een beroemdheid, hij was een veel gevraagd filmacteur en regisseur, publiceerde succesvolle handboeken en maakte een aantal tournees door West-Europa in het netwerk van de filmclubs. En de documentaire tURKSIB werd al meteen in de jaren dertig door John Grierson opnieuw gemonteerd en van nieuwe tussentitels voorzien voor de distributie in Amerika en Engeland. ${ }^{29}$

Het zal de lezer inmiddels duidelijk zijn dat ELIso wat mij betreft een meesterwerk is, dat niet zou misstaan in de canon van de zwijgende film in de SovjetUnie. Hoe komt een film op dit erepodium terecht? Dit is een vraag van alle tijden en alle kunsten. Filmwetenschapper Janet Staiger bespreekt in haar artikel 'The politics of film canons' de strategiekeuzes van filmwetenschappers bij de 
vorming van de filmcanon. In het begin was de strategie gericht op erkenning van het medium film als kunstvorm ('politics of admission'), pas na verloop van tijd werd het noodzakelijk een strategie te ontwikkelen voor de selectie van een kerngroep en de samenstelling van een rangschikking ('politics of selection' ofwel 'politics of inclusion and exclusion'). Staiger stelt dat de vorming van een filmcanon ingebed is in een groter netwerk van invloedrijke factoren. Ze bespreekt de rol van filmwetenschappers en de keuze van films binnen het universitair onderwijs. Ze benadrukt de rol van macht ('politics of power'): de vorming van een film canon hangt af van wat waardevol gevonden wordt en dit hangt af van welke stem het meeste gezag heeft. Dit is van toepassing op de programmering van filmerfgoed, maar ook op de filmgeschiedschrijving. Staiger benadrukt in de slotalinea's van haar artikel de invloed van de gevestigde macht op de vorming van de canon:

'The politics of film canons, however, does not cease at the level of admission or selection of films. Within a capitalist economy (and other economies), politics also exists in the film academy. Not only a canon of films exists but also a canon of literature about film and a canon of film methodologies. (...) Furthermore, networks of taste-makers support those who support them. Achieving recognition for marginal approaches is difficult in part because it threatens the center of power.' $3 \circ$

De laatste zin is bijna te karakteriseren als een orthodox marxistisch standpunt van reproductie van de dominante ideologie en in het geval van ELIso zou dit perspectief in historisch opzicht inderdaad toepasselijk genoemd kunnen worden. In meer algemene zin is de machtsstrijd binnen het netwerk van smaakmakers in de wereld van het filmerfgoed echter het beste meer neutraal te kenschetsen als een concurrentiestrijd zoals overal elders - een botsing tussen schaarste en overvloed. Meer opvallend is dat we bij zwijgende films nog steeds te maken hebben met de 'politics of admission', want de strijd om erkenning is nog niet klaar. Zwijgende film heeft een imagoprobleem constateerde ik aan het begin van dit artikel. We hebben te maken met een brede maatschappelijke onverschilligheid voor dit deel van het filmerfgoed. De experts onder elkaar maken zich in hun reservaat van cinefiele zonderlingen druk om de 'politics of selection', de reputatievorming van individuele filmers ('auteurs') en films (de canon, top tien lijsten). We kunnen inventariseren welk filmerfgoed in filmgeschiedschrijving terecht komt en welk filmerfgoed in de filmzaal vertoond wordt en zien dan dat de canon uiterst grillig en broos is. Roem is zo mogelijk nog vergankelijker dan nitraat. De benadering van Staiger biedt een basis voor nader onderzoek hiervan. 


\section{De programmeur als bruggenbouwer}

Voor de programmeur stopt het verhaal hier niet. Op het moment waarop de keuze van de te vertonen films is bepaald begint de vraag: hoe kan de pers worden verleid hierover te schrijven en het publiek worden verleid een kaartje te kopen. De eigentijdse Nederlandse filmcriticus en de toeschouwers moeten bij ELISo namelijk wel in staat zijn drie hordes te nemen: het trotseren van de 'geluidsbarrière', de tijdsbarrière en de cultuurbarrière, want we hebben het hier over een zwijgende film, uit I928, uit Georgië en het verhaal is ook nog eens gesitueerd in de negentiende eeuw. Wellicht is de eerste horde meteen de hoogste: zwijgende cinema is een dode filmtaal: ze worden niet meer gemaakt, op een enkele persiflage of pastiche na. De verbeeldingswereld van de zwijgende films is ver verwijderd van de eigentijdse toeschouwer. De programmeur moet zich opstellen als bruggenbouwer naar zijn beoogd publiek. In plaats van een gatekeeper is hij nu meer een cultural intermediar. Kunstsocioloog Keith Negus omschrijft deze term als volgt:

'The central strength of the notion of cultural intermediaries is that it places an emphasis on those workers who come in-between creative artists and consumers (or, more generally, production and consumption). It also suggests a shift away from unindirectional or transmission models of cultural production towards an approach that conceives of workers as intermediaries continually engaged in forming a point of connection or articulation between production and consumption.'3 ${ }^{\mathrm{I}}$

De cultural intermediar (cultureel intermediair) is dus de verbindingsfiguur tussen het aanbod (de collectie van het filmarchief) en de vraag (het publiek) en is invloedrijk als inspiratiebron en/of als initiatiefnemer van spraakmakende manifestaties en publicaties. In de wereld van het filmerfgoed is met een historische blik de hele pioniersgeneratie van de grondleggers van filmarchieven aan te duiden als cultural intermediars, met namen als Henri Langlois, Ernest Lindgren, Iris Barry, Jacques Ledoux en Jan de Vaal. ${ }^{22}$

In het voorgaande heb ik een indruk willen geven van de complexe samenhang van beslissingen van de verschillende gatekeepers in het algemeen, en rondom de vertoning van zwijgende films met muzikale begeleiding in het bijzonder. Het belang van het onderzoek naar institutionele verhalen is geschetst. Onderzoek naar deze achtergrondverhalen is noodzakelijk, want we stuiten op talloze onzekerheden. De invloed of macht van de verschillende gatekeepers bijvoorbeeld is niet eenduidig te schetsen, want het is heel goed mogelijk gatekeepers te omzeilen en geen enkele gatekeeper heeft een soevereine macht over zijn poort. Een gatekeepers moet zich zelf ook scharen in de stroom van toegangvragers bij diverse andere poorten en daarnaast lijkt het ook vaak alsof het 
toeval domineert boven elk soort beredeneerde beslissing. Een flexibele mix van intenties, beredeneerde keuzes en noodlot bepaalt hoe het selectieproces verloopt waarin films en musici uitverkoren worden voor het programma van een festival, een cinematheekprogramma of een restauratieproces. De verklaring van dit selectieproces is moeilijk te geven. Het startpunt hiervoor ligt in een zo volledig en systematisch mogelijke inventarisatie van de gatekeepers die betrokken zijn bij de ontsluiting van filmerfgoed. 33

* Met dank aan drs. Erik Daams (Filmhuis Den Haag), Arie van der Ent (slavist en uitgever), Rommy Albers en Henk van der Lingen (Filmmuseum) voor waardevolle informatie en medewerking. En met dank aan drs. Toine Minnaert (Universiteit Utrecht), drs. Anneke Mengerink (Universiteit Utrecht), dr. Philomeen Lelieveldt (Universiteit Utrecht), dr. Ivo Blom (vu) en de redactie van TMG voor hun constructief commentaar op eerdere conceptversies.

I J. Rifkin, The Age of Access. The new culture of hypercapitalism where all of life is a paid-for experience, New York 2000, p. 177.

2 Er bestaan vele variaties in de transcriptie van de regisseursnaam: Sjengelaja (Nederlands); Shengelaya (Engels); Chenguelaia of Sengelaia (Frans); Schengelaja (Duits). De filmtitel wordt als ELISO of ELISSO geschreven.

EuIso - Sovjet Unie 1928. Regie: Nikolaj Sjengelaja. Scenario: Sergej Tertjakov \& Nikolaj Sjengelaja, gebaseerd op het verhaal van Alexandr Kazbegi (Kazbek). Camera: Vladimir Kereselidze. Productie Goskinprom-Groezija, Georgië. Met: Kira Andronikasjvili, Kokta Karalasjvili, Aleksandr Imedasjvili, I. Mamporija, Aleksander Zorzoliani, T. Poetsoenava.

3 D.J. Youngblood, Soviet cinema in the silent era, 1918-1933, Austin I99I, p. I82.

4 Zie het seizoenoverzicht van de Nederlandse Filmliga, zoals opgenomen in een bijlage van C. Linssen, H. Schoots \& T. Gunning, Het gaat om de film! Een nieuwe geschiedenis van de Nederlandsche Filmliga 1927-1933, Amsterdam I999. Nader onderzoek van de details van de vertoningen van ELISO in I930 is noodzakelijk: wat is de exacte datum geweest? De databank van het Filmmuseum noemt 23 mei I 930 als Nederlandse premièredatum van Eliso. De website Cinema Context. Film in Nederland vanaf 1896. Een encyclopedie van de filmcultuur (www.cinemacontext.nl) noemt twee vertoningsplaatsen van ELIso in de jaren dertig, met als vroegste datum 24 mei 1930 (in Den Haag, Buitenhof 20) en als tweede datum 30 december 1930 (in Arnhem, gebouw Irene, Beekstraat 7I). Het betreft hier voorstellingen van de Nederlandsche Filmliga, zoals bevestigd wordt door het overzicht van de seizoenprogramma's van de Filmliga, opgenomen als bijlage in Linssen et al., Het gaat om de film! De uitvoering is echter een dag opgeschoven: In Den Haag staat op 25 mei I930 een programma vermeld dat bestaat uit NOGENT SUR MARNE (I929), DE ROOS VAN PU-CHUI (I927) en 'fragmenten uit door Ivens uit Sovjetunie meegebrachte films', te weten: ARSENAAL (I928), HET ELFDE JAAR (I928), ZVENIGORA (I928), ELISO (I928) en DE JEUGD OVERWINT (...). In Arnhem staat vermeld dat op 3I december I930 hetzelfde programma werd vertoond, met toevoeging van HooGSTRAAT (I930), een journaalmontage door Willem Bon en een voordracht van de Maria-legende De speelman door Charlotte Köhler.

5 De details van de drie kopieën van ELIso in het archief van het Filmmuseum, ontleend aan de databank van het Filmmuseum:

a Gv I6I = projectiekopie 35mm (versie van i964), normaalbeeld, geen tussentitels, zwartwit, met Russisch commentaar en dialogen (circa 1269 meter, bij I 8 b/s is dit circa 62 minuten). Op I februari I988 aangekocht van distributeur Classics (Amsterdam).

b Gz I069= projectiekopie $16 \mathrm{~mm}$, zwijgend (circa 880 meter, bij $24 \mathrm{~b} / \mathrm{s}$ is dit circa 80 minuten). Op 30 juli I990 ontvangen van Film International. 
c D235 = archiefkopie, $35 \mathrm{~mm}$, volbeeld, positief (circa 2190 meter, bij I8 b/s is dit circa 106 minuten), Nederlands ondertiteld. Op I november 1967 ontvangen van Sov-export.

Ter nuancering: de archiefkopie lijkt nog circa IIo meter te missen, want Leyda, Kino, p. 434 (zie nt. 26) en de website www.silentera.com vermelden bij ELIso een lengte van 2300 meter.

6 De distributiecollectie van Film International lag opgeslagen in de kelder van het kantoorpand Westersingel 20 in Rotterdam, zonder speciale voorzieningen. Zie: C. Gaemers, Achter de schermen van de kunst. Rotterdamse Kunststichting 1945-1995, Rotterdam I996, p. 95.

7 Zie J. Heijs \& F. Westra, Que la tigre danse: Huub Bals, een biografie, Amsterdam 1996, p. 40. Een beknopte aanvulling: François Albera schreef een artikel over de eigentijdse Sovjet cinema waarin hij ook een aantal Georgische regisseurs besprak. Dit artikel werd in $198 \mathrm{I}$ in het Nederlands vertaald: F. Albera, 'De Sowjet-Cinema. Rusland en de republieken', in: Film International Kwartaal, tijdschrift voor internationale filmkritiek (I98I/I) p. 38-43. De Franse versie werd in I986 gepubliceerd: 'Aggiornamento à l' Union des Cinéastes', in: Positif, nr. 310 (december I986) p. $22-26$.

Het Film International Kwartaal was een uitgave van het Film International Festival, onder redactie van Jan Heijs en Monica Tegelaar. Het heeft één jaargang bestaan: vier nummers in I98I. Filmcriticus François Albera was in de jaren tachtig ook docent aan de kunstacademie van Lausanne en is nu hoogleraar filmstudies aan de universiteit van Lausanne. In Nederland is hij vooral bekend als kenner van de films van Johan van der Keuken.

8 J. Heijs (red.), Catalogus Film International Rotterdam \# 10, Rotterdam I98I, p. 58-67.

9 E. Daams, 'Georgië, volgens Iosseliani, Rechwiaswili en Shenguelaia \& zonen', in: Kijkschrift, nr. 44, I98I, p. 2-5.

In I98I werden drie films van vader en zonen Sjengelaja aangekondigd in de catalogus van het Ioe festival Film International Rotterdam, in de rubriek 'wordt verwacht': DE 26 COM M ISSARISSEN (Nikolaj Sjengelaja, I933), TETRI KARAVANi (De witte karavaan, Eldar Sjengelaja, I963) en ALAVERдова (Twee verhalen, Giorgi Sjengelaja 1962). De genoemde films van de beide zonen konden niet aangekocht worden voor distributie. Van Eldar Sjengelaja werd later wel DE BLAUWE BERGEN (I983) en RARE VOGELS (I973) in Nederland uitgebracht en zijn jongere broer Giorgi Sjengelaja werd in Nederland bekend met Pirosmani (1969). Bronnen:

- J. Heijs (red.), Catalogus Film International Rotterdam \# 10, Rotterdam I98I, p. I33.

- J. Heijs \& W. Oosterbeek (red.), Distributiecatalogus. De Rotterdamse filmcollectie, Rotterdam I982, p. 48 \& p. 79.

- M. Hommel, M-P. Meyer \& G. Zuilhof (red.), Sovjetfilms. NFM/IAF distributiecatalogus, Amsterdam I99I, p. II4 e.v.

Io Zie o.a. B. Amengual, 'Cinéeurasie. Les Cinémas soviétiques d'Asie Centrale et de Transcaucasie au festival de Pesaro I985', Positif, nr. 310 (december 1986), p. 30-33; J. Radvanyi (red.), Le cinéma Georgien, Parijs 1988; Variety (april I9, 1989). De recensie verscheen naar aanleiding van de vertoning op het Hong Kong Film Festival van I989. Hier werd ook een andere onbekende Georgische zwijgende film vertoond: MY GRAN D м отHER (Kote Mikaberidze, 1929). Deze film was in 1976 gerestaureerd en in 1977 gepresenteerd op het New York Film Festival. In 2005 werd een jazz score bij deze film gecomponeerd door Beth Custer, in opdracht van het Pacific Film Archive (zie: www.bethcuster.com).

II Amsterdam (Kriterion, 27 april I98I), Den Haag (Studio 2000, 20 april I98I en Het Kijkhuis) en Rotterdam (Lantaren/Venster, nachtvoorstelling 24 en 25 april I98I). Bron: De Filmkrant, nulnummer, april ı98I, p 7. Integrale reprint in De Filmkrant, 276, april 2006.

I2 Over het vraagstuk van de authenticiteit van de kopie zie onder anderen: N. Carroll, 'Unwrapping Archives: DVD Restoration Demonstrations and the Marketing of Authenticity', in: The Velvet Ligt Trap, nr. 56 (najaar 2005) p. I8-31; P. Cherchi Usai, 'Geschiedenis en esthetiek van "de originele kopie”: een model voor analyse', in: Versus, I/1987, p. 75-105; F. Kessler, 'Filmgeschichte und Filmkopien', in: Synema (ed.), Auf der Suche nach dem Filmischen. Kinoschriften 5, Wenen 2002, p. I99209; M. Körber, 'Zur problematik des Originals in der Filmrestaurierung', in: Synema (red.), Auf der Suche nach dem Filmischen, Kinoschriften 5, Wenen 2002, p.I77-I88. 
I3 Ter vergelijking: de films van Sergej M. Eisenstein werden pas in de jaren vijftig in de Sovjet-Unie met muzikale begeleiding heruitgebracht. (Een rampzalige 'restauratie' overigens omdat de projectiesnelheid blindelings op 24 beeldjes per seconde werd ingesteld).

I4 De versie van I935 van eliso werd op I8 maart 2006 vertoond in het Filmmuseum van Frankfurt (www.deutsches-filmmuseum.de) en op ig maart in de Metropolis bioscoop in Hamburg (www.metropoliskino.de), in een programma dat georganiseerd was door het Deutsch-Kaukasische Gesellschaft (www.lile.de).

Waarschijnlijk is deze versie ook in 200I vertoond tijdens het 'Go East. Festival des Mittel und Osteuropäischen Films', in Wiesbaden, in het kader van het symposium 'Das Bild des Anderen: Kaukasus'. Zie: http://www.deutsches-filminstitut.de/goeast_2002/content/deutsch/rueckblick/ symposium_einleitung.htm

Overige vertoningen van deze versie zijn mij niet bekend.

I5 V.A. Alexander, Sociology of the arts. Exploring fine and popular forms, Malden 2003, p. 90.

I6 Zie ook onder anderen R. A. Peterson, 'Six constraints on the production of literary works', in: Poetics, jrg. I4 (1985), p. 45-67; E.A. Kuitert, 'Literair erfgoed: van oude vodden en klassieken', in: F. Grijzenhout (red.), Erfgoed. De geschiedenis van een begrip, Amsterdam 2007, p. 205-230.

I7 De begeleiding van ELIso door pianist Wim van Tuyl en sopraan Pien Straesser werd in 2005 voor het eerst gepresenteerd in het kader van de reeks 'Stomme Sovjets!', op maandag 24 oktober 2005, in het Filmhuis Den Haag. Noodgedwongen werd toen gebruik gemaakt van de kopie Gv I6I, zonder tussentitels. Deze voorstelling werd herhaald in Lantaren/Venster (Rotterdam) op I8 november 2007. Zie ook: P. Bosma \& E. Daams (red.), Programmabrochure Stomme Sovjets, Rotterdam/Den Haag 2005, p. I4-I5. Pianist Wim van Tuyl had eerder ervaring opgedaan met ELIso, door zijn solobegeleiding op 23 mei I999 in het Filmmuseum.

I8 Zie over de relatie tussen programmering en het filmarchief o.a.: B. Eisenschitz et al., 'Programming in Film Archives and the Evolution of Film History', in: FIAF: Rediscovering the role of film archives: to preserve and to show, Lissabon I989, p. 45-75; C. Jeavons, 'Programming from Archive Collections', in: H. Okajina (ed.), Four Tasks of Film Archives. Records of the International film symposium, 1990, Tokyo I992, p. II3-I20; D. Païni, Le temps exposé. Le cinéma de la salle au musée, Parijs 2002.

I9 De muzikale begeleiding van ELIso op IO april 2008 werd samengesteld door Wim van Tuyl (piano) en Pien Straesser (sopraan). Van Tsjaikovsky kozen ze het lied 'Nur wer die Senhnsucht kennt' (geselecteerd uit de verzameling Mignon liederen, de tekst van Goethe is vertaald in het Russisch). Dit lied over het verlangen naar de liefde wordt aan het begin van de film ingezet, wanneer Vazja het dorp van Eliso bezoekt en ze elkaar van een afstand heimelijk aankijken. Hun liefde is wederzijds, maar kan niet uitgesproken worden: hij is christelijk en zij is moslim. Het lied keert terug aan het eind, als ze smartelijk afscheid moeten nemen omdat de vader van Eliso hun verbintenis blokkeert. Van Moessorgski werd zijn bewerking van het traditionele Oekraiense danslied 'Hopak' gebruikt, bij de scène aan het begin van de film waarin de dorpsbewoners gezamenlijk een huis bouwen (de tekst van Sjevtsjenko gaat over kozakken en vrolijke dronkenschap). Shostakovitsj kwam aan bod met het lied 'The city sleeps' bij de scène waarin het herdersjongetje huilend komt melden dat het vee is gestolen. Van dezelfde componist klonk ook het 'Lied van Ophelia' (beide liederen maken deel uit van de Zeven Romances naar gedichten van Alexander Blok, opus I27, I967). Bij de charge van de Kozakken op de weerloze dorpelingen klonk het lied 'Through the leafy forest' van Sjedrin. Als de dorpelingen aan hun uittocht beginnen klinkt de melancholieke aria van Tsjaikovsky 'Farewell, dear land, familiair fields and meadows' (uit de opera Jeanne d'Arc). Bij de sterfscène van de dorpsvrouw tijdens de exodus klonk een tweede lied van Moessorgski, een dramatische Serenade (ofwel 'Ständchen', uit de verzameling liederen en dansen van de dood, gecomponeerd in 1870 , op tekst van A. Golenisjtsjev-Kutusov).

20 De zwijgende film kent een toenemend aantal gespecialiseerde internationale festivals. Sinds 198I bestaat het festival Giornate del Cinema Muto in Pordenone, vijf jaar later ontstond het festival Il Cinema Ritrovato in Bologna. In de jaren negentig werden meer filmerfgoed-festivals begonnen, onder andere in Parijs (Cinémémoire, sinds I99I), in San Francisco (het San Francisco Silent Film Festival, sinds 1996) en in Nottingham (British Silent Cinema Festival, sinds 1998). Het Filmmuseum in Amsterdam begon in 2003 de reeks van Filmmuseum Biënnales. Voor een meer 
uitvoerig overzicht zie de website www.stummfilm.info. Daarnaast zijn zwijgende films op diverse internationale filmfestivals te zien, zoals het London Film Festival, het Internationaal Filmfestival Vlaanderen in Gent en sinds kort ook het Filmfestival van Cannes (de serie Cannes Classics). Over het verschijnsel internationale filmfestivals, zie o.a. M. de Valck, Film Festivals. From European geopolitics to global cinephilia. Amsterdam 2007.

2I Zie mijn DVD-bespreking van BEYOND THE ROCKs, in: TMG, jrg. IO, nr. I, 2007, p. II6-II9. BEYOND THE ROCKS werd in 2006 gepresenteerd in het kader van Cannes Classics en via een tournee langs filmtheaters, filmarchieven en filmfestivals in de Verenigde Staten.

22 Voor 'Beelden voor de toekomst' is een fors bedrag toegekend: I73 miljoen euro. Het geld is afkomstig van het Fonds Economische Structuurversterking (FES) en is deels een lening: met de exploitatie van het gerestaureerde materiaal moeten de archieven 83 miljoen euro verdienen en terugstorten in het fonds. De archieven moeten zich waarmaken als culturele ondernemers. De netto investering van de overheid bedraagt dus 90 miljoen euro. Dit bedrag wordt uitgesmeerd over een periode van zeven jaar en verdeeld over de zes participanten. Wat blijft netto over per instelling? Het Filmmuseum bijvoorbeeld ontvangt in het kader van 'Beelden voor de toekomst' in totaal 35 miljoen, een aanzienlijk bedrag dat onder andere gebruikt gaat worden voor de digitalisering van de collectie. 'Beelden voor de toekomst' betekent dus een grote stap vooruit op het gebied van conserveren en ontsluiten van audiovisueel erfgoed, maar voor tevreden achterover leunen is het nog te vroeg: in Nederland blijft ongeveer 400.000 uur audiovisueel materiaal over dat niet aan de beurt komt. De vraag is dan ook: hoe verloopt de selectie van materiaal dat binnen het project 'Beelden voor de toekomst' behandeld kan worden?

23 De coördinatie van de begeleiding van zwijgende films in het Filmmuseum berust bij muziekmedewerker Martin de Ruiter, die kan beschikken over drie 'huispianisten' (de vaste freelancers Wim van Tuyl, Yvo Verschoor en Charles Janko) en aanvullende beschikbare musici. Zie de website www.filmmuseum.nl.

24 Theodore van Houten organiseerde vanaf 1982 voorstellingen met zwijgende films, begeleid door orkest of kleine bezettingen. Aanvankelijk als werknemer bij het Brabants Orkest en vanaf I993 als kleine zelfstandige met een eigen stichting Film in concert (voorheen Silent Cinema Music Live). Hij combineerde hierbij de functies van artistiek directeur, onderzoeker, programmeur, impresario en publiciteitsmedewerker. De stichting Film in concert werd in 2006 opgeheven wegens geldgebrek. Van de groep betrokken musici en componisten kan Maud Nelissen als de meest succesvolle worden aangemerkt (zie o.a. de website www.sprockets.nl). Over de portfolio van Theodore van Houten zie o.a. Th. van Houten, 'Programmabrochure nieuw Babylon', Nijmegen I982; Th. van Houten, 'Programmabrochure nApoleon', bijlage bij Skrien, I38 (nov/dec I984); Th. van Houten, Leonid Trauberg and his films, Den Bosch/Buren I989; Th. van Houten, Eisenstein was great eater, Den Bosch/Buren I99I; M. Khalifa, 'Het Brabants Orkest begeleidt zwijgende films. Van NAPOleon tot JEANne d' ARC', in: H. Straub \& A. van Campen et al. (red.), Een bevlogen orkest uitgelicht. Het Brabants Orkest 1950-2000, Bussum/Eindhoven 2000, p. 67-73; P. van Yperen, 'De herontdekking van een kunstvorm. Theodore van Houten over levende muziek', in: Skrien, jrg. 33, nr. 9 (nov. 200I) p. 36-39.

25 Philomeen Lelieveldt heeft onder andere de loopbaanmogelijkheden van de bioscoopmusici in de jaren twintig onderzocht in haar dissertatie: Ph.B. Lelieveldt, Voor en achter het voetlicht: Musici en de arbeidsverhoudingen in het kunst- en amusementsbedrijf in Nederland, 1918-1940. Amsterdam 1998. Ze geeft hierin een eerste inventarisatie van orkestleiders (onder anderen Max Tak, Hugo de Groot) en musici (onder anderen Bernhard Drukker, Ido Eyl) en vertoningspraktijken (onder andere Cinema Royal, Tuschinski Theater, Rembrandt Theater). Voor deelstudies over Nederlandse bioscoopmusici zie o.a. B. Drukker, Ik speel voor u, Nieuwkoop I979 (autobiografie); J. Groeneboer, 'Het orkest van Cinema Royal', in: Versus, 5 (I988) p. 73-96; J. Groeneboer, 'Hugo de Groot (I897I986). Een muzikaal leven in de film', in Jaarboek Mediageschiedenis, 6 (I995) p. I44-I64; Th. van Houten, Silent cinema music in the Netherlands. The Eyl/Van Houten collection offilm and cinema music in the Nederlands Filmmuseum, Buren I992; M. Tak, Onder de bomen van het plein, Amsterdam I962 (autobiografie). 
26 J. Leyda, Kino: A History of the Russian and Soviet Film, Princeton I983 [I960], p. 273. Terzijde: De vrouwen van RJaZAn (Olga Preobrazjenskaja, 1927) werd in Nederland in de jaren tachtig aangekocht door distributeur Cinemien.

27 A. Groschew, et al. (red), Der sowjetische Film, Berlijn 1974. Oorspronkelijk een uitgave van het wGIK in Moskou, I969; J. Toeplitz, Geschichte des Films, Band I. 1895-1928, Berlijn I984 [I972].

28 D. J. Youngblood, Soviet cinema in the silent era, 1918-1933, Austin I99I, p. I8I-I82.

EuIso (1928) is echter verder onvindbaar in o.a.: D. Gillespie, Early Soviet Cinema. Innovation, Ideology and Propaganda, Londen 2000; A. Lawton (ed.), The Red Screen: politics, society, art in Soviet cinema, New York 1992; P. Kenez, Cinema and Soviet society, 1917-1953, New York I992; D.J. Youngblood, Movies for the Masses. Popular cinema and Soviet society in the 1920's, New York 1992.

29 Over turкsiв zie o.a.: K.J. Coldicutt, 'тU Rкsi : Building a Railroad', in: Bulletin of the Realist Film Association (Melbourne, april I933). Herdrukt in: L. Jacobs (ed.), The Documentary Tradition, New York 1979, p. 45-48. Tevens herdrukt in: Screening the past, nr. 2 (december 1997), URL: www. latrobe.edu.au/screeningthepast/classics/clasdec/Coldı.html; M. Payne, 'Viktor Turin's turksib (1929) and Soviet Orientalism', in: The Historical Journal of Film, Radio and Television, jrg. 2I, nr. I (maart 200I) p. 37-62; D. Williams, 'Screening Coldicutt: Introduction', in: Screening the Past, nr. 2 (december 1997), URL: www.latrobe.edu.au/screeningthepast/classics/clasdec/cold.html

30 J. Staiger, 'The politics of film canons', in: Cinema Journal, jrg. 24 nr. 3 (voorjaar I985) p. I8-I9.

3I K. Negus, 'The work of cultural intermediaries and the enduring distance between production and consumption', in: Cultural Studies, jrg. I6, nr. 4 (juli 2002) p. 503.

32 P. Cherchi Usai, Silent cinema: An introduction. Londen 2000 (2e druk), p. 77 e.v. In een meer recent verleden is bijvoorbeeld te wijzen op het omvangrijke en veelzijdige werk van Britse filmhistorici zoals Kevin Brownlow en David Robinson. In Nederland hebben we profijt van energieke cinefielen als Erik de Kuyper, Peter Delpeut, Theodore van Houten en Bert Hogenkamp.

33 Voor internationaal historisch onderzoek naar de muzikale begeleiding van zwijgende films zie onder anderen:

- R. Abel \& R. Altmann (ed.), The Sounds of Early Cinema, Bloomington 200r;

- M.M. Marks, Music and the Silent Film. Contexts and Case Studies 1895-1924, New York 1997.

Voor bespreking van eigentijdse begeleidingen van zwijgende film in Nederland zie onder anderen:

- P. Bosma, 'THE Wind in de concertzaal', in: Skrien, jrg. 37, nr. I (feb 2005) p. 46-47.

- P. Bosma, 'Componist Maud Nelissen over the Patsy', in: Skrien, jrg. 37, nr. 3 (april 2005), p. 29.

- P. Bosma, 'Hoe ondersteun je vrouwenlijden met muziek? Vijf studenten compositie buigen zich over een klassiek melodrama', in: Skrien, jrg. 38, nr. 8 (oktober 2006) p. 22-23.

- C. Linssen, 'La Belle dame sans merci. De venijnige kracht van de liefde', in: Skrien 212 (febmaart I997) p. 32-33.

- G. Linthorst, 'Georgiërs: babY RJAZANSKije, een gesprek met componiste Ig Henneman', in: de Filmkrant, nr. 44 (maart I985) p. 7-8.

- P. van de Merwe, 'Na zeventig jaar eindelijk zoals het hoort. Zwijgende films met geluid', in: Skrien, jrg. 35, nr. 5 (juni/juli 2003) p. 34-35. 